\title{
Influences of Geological Conditions on the Soil Environment in Paddy Fields under Saturated Irrigation
}

\author{
Tomoki Izumi ${ }^{1}$ and Junichiro Takeuchi ${ }^{2}$
}

\begin{abstract}
In an attempt to counter heat damage to rice plants, the influences of geological conditions in paddy fields on the subsurface water flow and soil temperature for saturated irrigation are clarified by simulating the soil water movement and heat transport. Considering paddy fields located in a lowland or an alluvial fan as the geological conditions of the target area, the simulations of the water movement and heat transport in soil are carried out over 20 days, corresponding to the ripening period of rice grain. The results indicated that the time-varying soil temperatures and the average soil temperature of the lowland paddy field were lower than those of the alluvial fan, and thus the effect of saturated irrigation depends on the geological conditions of paddy fields under its implementation.
\end{abstract}

Keywords: Heat damage; Subsurface water flow; Soil temperature; Lowland; Alluvial fan

\section{Introduction}

In recent years, heat damage to rice plants (Oryza sativa) has been frequently reported, and various countermeasures have been proposed (e.g., Morita, 2008).

Spillover irrigation and deep-ponding irrigation, which decrease air and soil temperatures, are countermeasures related to irrigation water management. However, these countermeasures are difficult because agricultural water supply sectors, such as land improvement districts, cannot meet the additional irrigation water demands due to limitations involving water rights and irrigation facilities (Tomosho and Yamashita, 2009). On the other hand, Nagahata et al. (2005) reported that keeping soil saturated rather than ponding, i.e., saturated irrigation, was effective in avoiding heat damage to some extent. As such, saturated irrigation is a water-saving countermeasure and is very important in areas where meeting additional irrigation water demands is difficult. Fujihara et al. (2013) compared the soil environment and rice quality achievable by saturated irrigation and ponding irrigation and discussed the relation between the average air temperature after ear emergence and rice quality. However, there have been few studies on the effects of saturated irrigation.

Although one of the purposes of saturated irrigation is to decrease soil temperature in paddy fields, the temperature depends on the saturation of the soil. The soil water distribution is determined by the geology originating from the topographical condition. In Japan, paddy fields are developed on land characterized by various topographies such as mountainous lands, alluvial fans, and lowlands. Thus, it is important to consider the geological conditions in paddy fields.

In the present study, the influences of geological condi-

\footnotetext{
${ }^{1}$ Assistant Professor, Faculty of Agriculture, Ehime University, 3-5-7 Tarumi, Matsuyama, Ehime 790-8566, Japan (Corresponding Author) E-mail: t_izumi@agr.ehime-u.ac.jp

${ }^{2}$ Assistant Professor, Graduate School of Agriculture, Kyoto University, Kitashirakawa-oiwake-cho, Sakyo-ku, Kyoto 606-8502, Japan
}

tions on the soil environment (distribution of soil water and soil temperature) are discussed based on simulations of soil water movement and heat transport.

\section{Governing equations}

The mathematical models for soil water movement and heat transport based on Izumi et al. (2012), in which the model used had been validated with observed data, are used in the present study and described in the following subsections.

\subsection{Soil water movement}

The mixed form of the Richards equation is used to obtain mass-conservative numerical solutions for soil water movement (Huyakorn and Pinder, 1983; Celia et al., 1990). Assuming that the liquid phase has a relatively large magnitude (i.e., neglecting the vapor fluxes), the equation for saturated-unsaturated flow is as follows:

$$
\phi \frac{\partial S_{\mathrm{w}}}{\partial t}+W S_{\mathrm{w}} S_{\mathrm{s}} \frac{\partial \psi}{\partial t}=-\nabla \cdot\left(-K\left(\nabla h+\frac{\rho\left(T_{\mathrm{s}}\right)-\rho_{\mathrm{r}}}{\rho_{\mathrm{r}}} \nabla z\right)\right)
$$

with

$$
\begin{gathered}
W= \begin{cases}1 & (\psi \geq 0) \\
0 & (\psi<0)\end{cases} \\
S_{\mathrm{s}}=\rho_{\mathrm{r}} g\left(\beta_{\mathrm{s}}+\phi \beta_{\mathrm{w}}\right) \\
K=K_{\mathrm{r}}\left(S_{\mathrm{e}}\right) K_{\mathrm{T}}\left(T_{\mathrm{s}}\right) K_{\mathrm{s}} \\
h=\frac{p}{\rho_{\mathrm{r}} g}+z=\psi+z
\end{gathered}
$$

where $\phi$ is the porosity, $S_{\mathrm{w}}$ is the saturation, $S_{\mathrm{s}}$ is the specific storage, $\psi$ is the pressure head, $K$ is the unsaturated hydraulic conductivity, $h$ is the hydraulic head, $t$ is the time, $z$ is the height defined as positive upward, $\rho\left(T_{\mathrm{s}}\right)$ is the water density at the soil temperature $T_{\mathrm{s}}, \rho_{\mathrm{r}}\left(=\rho\left(T_{\mathrm{r}}\right)\right)$ is the reference water density at the reference soil temperature $T_{\mathrm{r}}, g$ is 
gravitational acceleration, $\beta_{\mathrm{s}}$ and $\beta_{\mathrm{w}}$ are the compressibility coefficients of soil and water, respectively, $K_{\mathrm{r}}$ is the relative hydraulic conductivity, $K_{\mathrm{T}}$ is the correction-factor function of soil temperature, $K_{\mathrm{s}}$ is the saturated hydraulic conductivity, $S_{\mathrm{e}}$ is the effective saturation, and $p$ is the water pressure.

\subsection{Heat transport}

A heat conduction equation based on Kondo and Saigusa (1994) is used in the investigation of heat transport, under the assumption that the heat flux due to the water movement in soil is smaller than the heat conduction by solid soil, as follows:

$$
\frac{\partial\left(C_{\mathrm{h}} T_{\mathrm{s}}\right)}{\partial t}=-\nabla \cdot\left(-\lambda \nabla T_{\mathrm{s}}\right)
$$

with

$$
\begin{aligned}
& C_{\mathrm{h}}=(1-\phi) c_{\mathrm{s}}+\theta c_{\mathrm{w}} \\
& \lambda=b_{1}+b_{2} \theta+b_{3} \theta^{0.5}
\end{aligned}
$$

where $C_{\mathrm{h}}$ is the volumetric heat capacity of soil, $\theta$ is the volumetric water content, $c_{\mathrm{s}}$ and $c_{\mathrm{w}}$ are the volumetric heat capacity of soil particles and of water, respectively, $\lambda$ is the thermal conductivity of soil expressed by Chung and Horton (1987), and $b_{1}, b_{2}$ and $b_{3}$ are the model parameters.

\subsection{Soil hydraulic properties}

For the soil hydraulic properties, the soil water retention curve, and the unsaturated hydraulic conductivity, the following models are used.

The VG model (van Genuchten, 1980) is used for the soil water retention curve because of the frequent simulation of water movement in soil:

$$
S_{\mathrm{e}}(\psi)=\frac{1}{\left(1+(\alpha|\psi|)^{n_{\mathrm{vg}}}\right)^{m_{\mathrm{vg}}}}=\frac{\theta-\theta_{\mathrm{r}}}{\theta_{\mathrm{s}}-\theta_{\mathrm{r}}}
$$

with

$$
m_{\mathrm{vg}}=1-\frac{1}{n_{\mathrm{vg}}}
$$

where $\theta_{\mathrm{r}}$ is the residual water content, $\theta_{\mathrm{s}}$ is the saturated water content, and $\alpha, m_{\mathrm{vg}}$ and $n_{\mathrm{vg}}$ are the model parameters.

Unsaturated hydraulic conductivity is described as the product of three variables shown in Eq. (4). Three variables, namely, the correction-factor function of soil temperature, the saturated hydraulic conductivity, and the relative hydraulic conductivity, are represented as follows:

$$
\begin{gathered}
K_{\mathrm{T}}=\frac{\mu_{\mathrm{r}}}{\mu\left(T_{\mathrm{s}}\right)} \\
K_{\mathrm{s}}=\frac{\rho_{\mathrm{r}} g \kappa}{\mu_{\mathrm{r}}} \\
K_{\mathrm{r}}=S_{\mathrm{e}}^{1 / 2}\left(1-\left(1-S_{\mathrm{e}}^{1 / m_{\mathrm{vg}}}\right)^{m_{\mathrm{vg}}}\right)^{2}
\end{gathered}
$$

where $\mu_{\mathrm{r}}\left(=\mu\left(T_{\mathrm{r}}\right)\right)$ and $\mu\left(T_{\mathrm{s}}\right)$ are the viscosity coefficient at the reference temperature $T_{\mathrm{r}}$ and soil temperature $T_{\mathrm{s}}$, respectively, and $\kappa$ is the intrinsic permeability.

\subsection{Discretization and initial/boundary conditions}

Equations (1) and (6) are discretized using the combination of the standard Galerkin finite element method for space and the finite difference method for time. As the time integral scheme, the implicit method with modified Picard method based on Celia et al. (1990) is used for the soil water movement, and the Crank-Nicolson method is used for the heat transport.

After discretization mentioned above, the governing equations are subjected to the following initial and boundary conditions and are solved numerically with the iterative partitioned method in terms of coupling the water movement with heat transport:

$$
\begin{gathered}
\psi(\boldsymbol{x}, 0)=\psi_{0}(\boldsymbol{x}) \text { in } \Omega \\
T_{\mathrm{s}}(\boldsymbol{x}, 0)=T_{0}(\boldsymbol{x}) \text { in } \Omega \\
\psi(\boldsymbol{x}, t)=\bar{\psi}(\boldsymbol{x}, t) \text { on } \Gamma_{\mathrm{d}}^{\mathrm{w}} \\
T_{\mathrm{s}}(\boldsymbol{x}, t)=\bar{T}_{\mathrm{s}}(\boldsymbol{x}, t) \text { on } \Gamma_{\mathrm{d}}^{\mathrm{h}} \\
-K_{\mathrm{s}} K_{\mathrm{r}} \frac{\partial h(\boldsymbol{x}, t)}{\partial \boldsymbol{n}}=\bar{q}_{\mathrm{w}}(\boldsymbol{x}, t) \quad \text { on } \Gamma_{\mathrm{n}}^{\mathrm{w}} \\
-\lambda \frac{\partial T_{\mathrm{s}}(\boldsymbol{x}, t)}{\partial \boldsymbol{n}}=\bar{q}_{\mathrm{h}}(\boldsymbol{x}, t) \text { on } \Gamma_{\mathrm{n}}^{\mathrm{h}}
\end{gathered}
$$

where $\psi_{0}(\boldsymbol{x})$ and $T_{0}(\boldsymbol{x})$ are the initial values of the pressure head and the soil temperature, respectively, $\boldsymbol{x}\left(=(x, z)^{\mathrm{T}}\right)$ is the vertical two dimensional vector, $\Omega$ is the space domain, $\bar{\psi}(\boldsymbol{x}, t)$ and $\bar{T}_{\mathrm{s}}(\boldsymbol{x}, t)$ are the values of the pressure head and soil temperature on the Dirichlet boundary, respectively, $\Gamma_{\mathrm{d}}^{\mathrm{w}}$ and $\Gamma_{\mathrm{d}}^{\mathrm{h}}$ are the Dirichlet boundaries for the water movement and heat transport, respectively, $\bar{q}_{\mathrm{w}}(\boldsymbol{x}, t)$ and $\bar{q}_{\mathrm{h}}(\boldsymbol{x}, t)$ are the water and heat fluxes on the Neumann boundary, respectively, $\Gamma_{\mathrm{n}}^{\mathrm{w}}$ and $\Gamma_{\mathrm{n}}^{\mathrm{h}}$ are the Neumann boundaries for the water movement and heat transport, respectively, and $\boldsymbol{n}$ is the outward unit normal vector on the boundary.

The water and heat fluxes on the ground surface are calculated as follows:

$$
\begin{gathered}
\left.\bar{q}_{\mathrm{w}}\right|_{\Gamma_{\mathrm{n}} \cap \Gamma_{\mathrm{s}}}=P-E \\
\left.\bar{q}_{\mathrm{w}}\right|_{\Gamma_{\mathrm{n}} \cap \Gamma_{\mathrm{s}}}=R_{\mathrm{n}}-H-l E
\end{gathered}
$$

where $\Gamma_{\mathrm{s}}$ is the ground surface boundary, $P$ is the precipitation flux, $E$ is the evaporation flux, $R_{\mathrm{n}}$ is the net radiation flux, $H$ is the sensible heat flux, and $l$ is the latent heat. The evaporation flux $E$ is estimated as the correction of the potential evaporation flux obtained from the classical Penman's method (Arai, 2004). The net radiation flux $R_{\mathrm{n}}$ is the radiation budget of short- and long-wave, and estimated as follows:

$$
R_{\mathrm{n}}=(1-a) S-\sigma T_{\mathrm{s}}^{4}\left(1-0.51-0.066 \sqrt{e_{\mathrm{a}}}\right)
$$

where $a$ is the albedo of the ground, $S$ is the solar radiation, $\sigma$ is the Stefan-Boltzmann constant, and $e_{\mathrm{a}}$ is the vapor 
pressure. The sensible and latent heat fluxes are obtained from the bulk formula as follows (Kondo, 1994):

$$
\begin{gathered}
H=c_{\mathrm{p}} \rho_{\mathrm{a}} C_{\mathrm{H}} U\left(T_{\mathrm{s}}-T_{\mathrm{a}}\right) \\
l E=l \rho_{\mathrm{a}} \beta C_{\mathrm{H}} U\left(q_{\mathrm{sat}}\left(T_{\mathrm{s}}\right)-q_{\mathrm{a}}\right)
\end{gathered}
$$

with

$$
\begin{gathered}
\rho_{\mathrm{a}}=1.293 \frac{273.15}{T_{\mathrm{a}}}\left(\frac{p_{\mathrm{a}}}{1013.25}\right)\left(1-0.378 \frac{e_{\mathrm{a}}}{p_{\mathrm{a}}}\right) \\
q_{*}=\frac{0.622\left(e_{*} / p_{\mathrm{a}}\right)}{1-0.378\left(e_{*} / p_{\mathrm{a}}\right)} \\
e_{\text {sat }}=6.1078 \times 10^{7.5\left(T_{\mathrm{s}}-273.15\right) / 237.3+\left(T_{\mathrm{s}}-273.15\right)}
\end{gathered}
$$

where $c_{\mathrm{p}}$ is the specific heat of air, $\rho_{\mathrm{a}}$ is the air density, $C_{\mathrm{H}}$ is the bulk transfer coefficient, $U$ is the wind velocity, $T_{\mathrm{a}}$ is the air temperature, $\beta$ is the evaporation efficiency, $q_{\mathrm{sat}}\left(T_{\mathrm{s}}\right)$ is the saturated specific humidity at $T_{\mathrm{s}}, q_{\mathrm{a}}$ is the air specific humidity, $p_{\mathrm{a}}$ is the air pressure, $e_{\text {sat }}$ is the saturated vapor pressure, and the subscript * denotes "sat" or "a".

\section{Numerical experiments}

The influences of geological conditions in paddy fields under saturated irrigation on soil water movement and soil temperature are analyzed using the numerical models mentioned above.

\subsection{Computational domain and cases}

In the present study, the computational domain is a two-dimensional vertical cross-section of a paddy field. As shown in Figure 1, we concentrate on part of the paddy field connecting the drainage canal.

For the purpose of the present study, the works of Imagawa et al. (2012) and Buma et al. (2012), which include the geological investigation in their targeting alluvial plain, are referred to. In order to consider the geological conditions, thus, two representative paddy fields in a lowland and an alluvial fan are assumed. The lowland paddy field has only one soil layer (humic silt), whereas the alluvial fan paddy field has two soil layers (humic silt in the upper layer and sand gravel in the lower layer) because alluvial fans are formed by river sedimentation and thus have a sand gravel layer near the ground surface. Accordingly, all of the layers are humic silt layers in the computational grid for the lowland paddy field, whereas the top three layers related to the plow layer are humic silt layers and the residuals related to the subsoil layer are sand gravel layers in the computational grid for the alluvial fan paddy field.

\subsection{Computation period and initial/boundary conditions}

The computation period used in the present study is 20 days, from August 1st to August 20th, 2008, corresponding to the ripening period of rice grain, since Koshihikari, the major brand in Japan, generally tassels between late July and early August.

In the initial condition, the values of pressure heads and soil temperatures, which are obtained from the preliminary

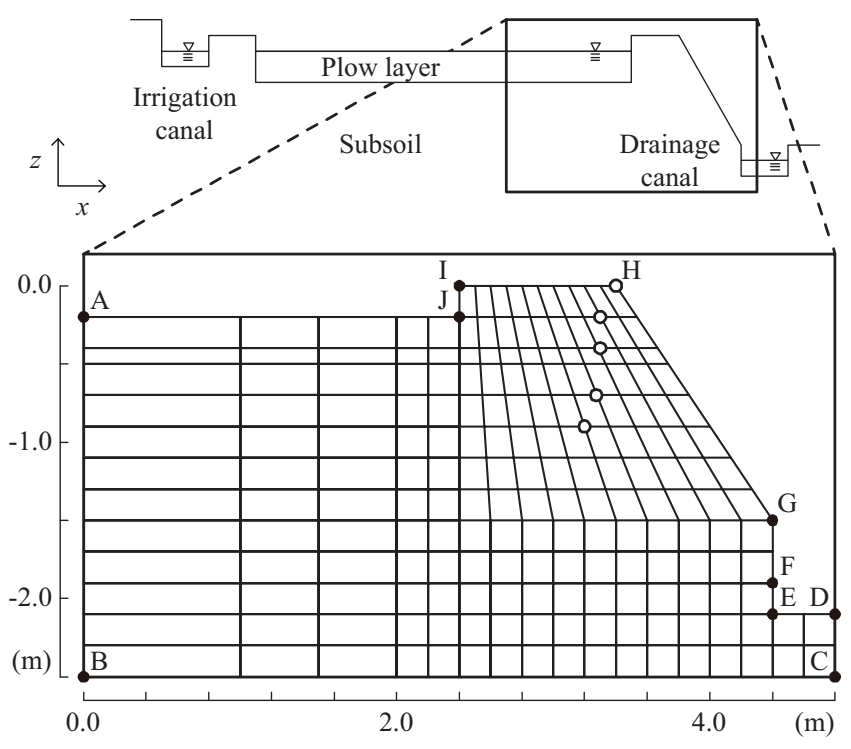

Figure 1: Computational domain and grid

computation during 5 days from July 25th to July 31st, 2008 , are assigned to all of the nodes in the computational grid. The time-varying pressure heads and soil temperatures are computed with the fixed time increment of $1.0 \mathrm{~s}$ under the initial condition and the boundary condition explained below.

The boundary conditions are set as follows. There are four boundaries in the computational domain: (i) the ground surface (A-J-I-H-G-F, in Figure 1), (ii) the lateral in the left-hand side (A-B), (iii) the bottom (B-C), and (iv) the drainage canal (C-D-E-F).

For the water movement, (i) is additionally divided into the surface in the paddy field (A-J) and the surface in the levee (J-I-H-G-F). In the former case, the Dirichlet boundary condition is assumed, and the pressure head $\psi=0$ $\mathrm{mH}_{2} \mathrm{O}$ is assigned to express the saturated irrigation condition. In the latter case, the Neumann boundary condition is assumed, and the flux obtained from Eq. (20) is assigned. In (ii) and (iii), the Neumann boundary condition is posed, and zero flux is assigned. In (iv), the Dirichlet boundary condition is assumed, and the pressure head corresponding to the water depth $(20 \mathrm{~cm})$ in the canal is assigned.

For the heat transport, the Neumann boundary condition is assumed, and the flux of the ground heat is assigned in (i). In (ii), (iii), and (iv), the Neumann boundary condition is also assumed, and zero flux is assigned.

The water and heat fluxes are calculated from Eqs. (20) through (27) and the actual meteorological data obtained from Imazu, Shiga Prefecture, in 2008, as shown in Figure 2. Figure 2 also includes the time-varying evaporations which are estimated in the way explained in the section 2.4. The product of $C_{\mathrm{H}} U$ in Eqs. (23) and (24) is referred to as the exchange speed, and is described as the function of wind velocity by Kondo (2000). In this paper, thus the following function is employed for the exchange speed of paddy fields:

$$
C_{\mathrm{H}} U=0.006 U_{10}
$$


with

$$
U_{10}=U_{z} \frac{\ln 10 / z_{0}}{\ln z_{\mathrm{obs}} / z_{0}}
$$

where $U_{10}$ is the wind velocity at $10 \mathrm{~m}, U_{z}$ is the wind velocity at observed height $z_{\mathrm{obs}}, z_{0}$ is the roughness length for wind velocity.

The parameter values used in the present study are summarized in Table 1 and 2. Table 1 shows the soil parameters based on Buma et al. (2012). Table 2 shows the common parameters in this computation. The compressibility coefficient of soil is inversely calculated from the specific storage based on Anderson and Woessner (1992). The volumetric heat capacity of soil and water, the albedo, and the evaporation efficiency are based on Kondo (1994). The model parameters relating the thermal conductivity are based on Chung and Horton (1987). The roughness length is based on Kondo (2000).

\subsection{Results and discussion}

First, the distribution of the pressure head, the total head (containing the flow velocity vector), and the soil temperature at 12:00 on August 13th, where the maximum soil temperature is obtained near the soil surface, are shown in Figures 3 through 8 . The components of flow velocity vectors are calculated as follows:

$$
u_{x}=-K \frac{\partial h}{\partial x}, \quad u_{z}=-K\left(\frac{\partial h}{\partial z}+\frac{\rho\left(T_{\mathrm{s}}\right)-\rho_{\mathrm{r}}}{\rho_{\mathrm{r}}}\right)
$$

where $u_{x}$ and $u_{z}$ are the horizontal and vertical component of flow velocity, respectively.

Comparison of Figures 3 and 6 reveals that the ground water surface connects from the ground surface of the paddy field to the drainage canal in both paddy fields. The differences are not clear. Comparison of Figures 4 and 7 reveals that the flow field moving toward the drainage canal is formed in both paddy fields. The differences in the flow velocity at the domain below the plow layer are clear. Comparison of Figures 5 and 8 reveals that the soil temperature in the lowland paddy field is lower than that in the alluvial fan for the entire domain, although there is little difference near the ground surface.

Second, the time-varying soil temperatures at depths of 0 $\mathrm{cm}, 20 \mathrm{~cm}, 40 \mathrm{~cm}, 70 \mathrm{~cm}$, and $90 \mathrm{~cm}$ (white circles in Figure 1) in the alluvial fan and the lowland are shown in Figures 9 and 10, respectively, in order to clarify the differences between the two paddy fields. Moreover, the difference in the soil temperatures between the two paddy fields is shown in Figure 11.

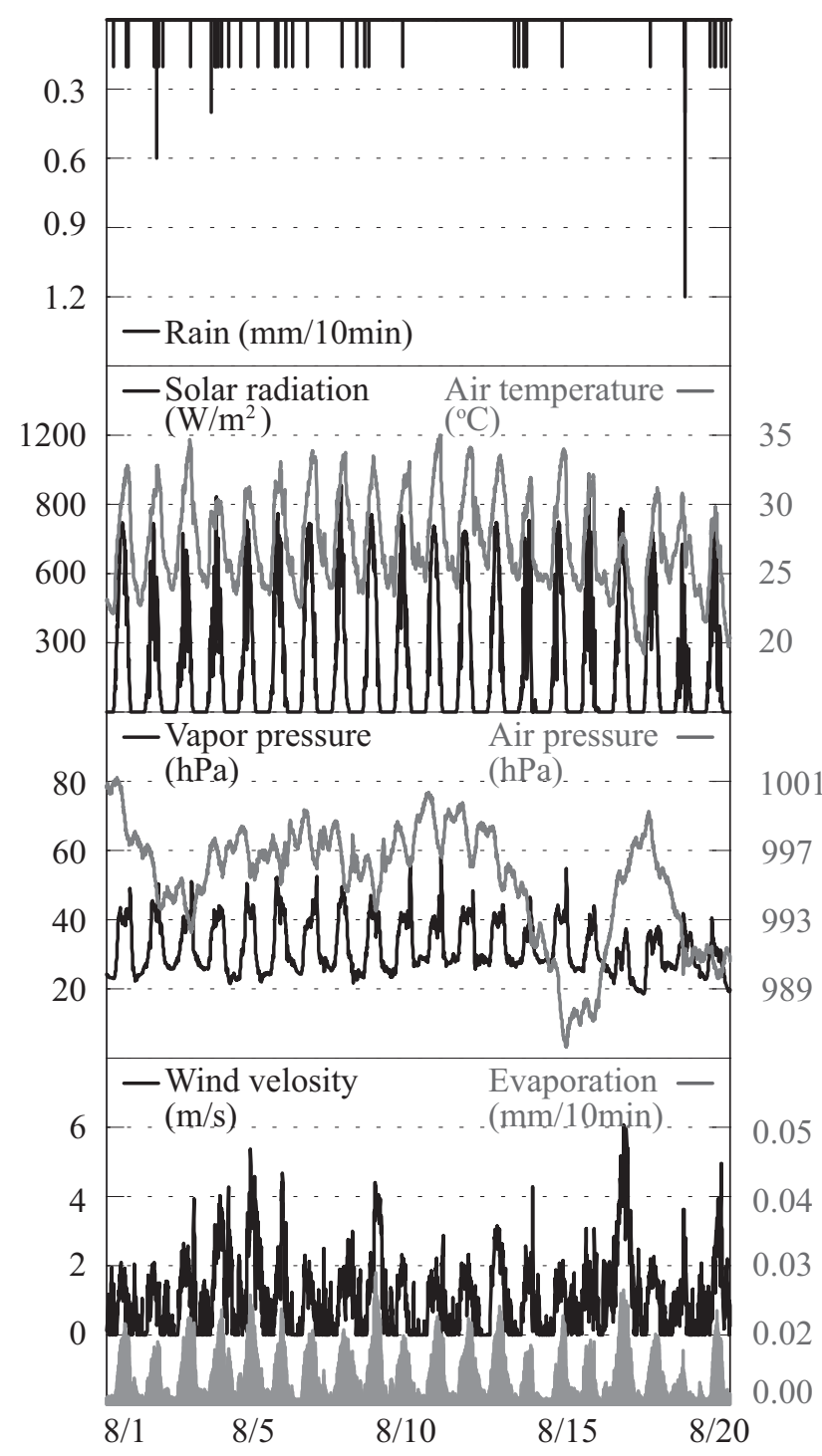

Figure 2: Meteorological data reported in Imazu (2008)

Table 1: Soil parameters

\begin{tabular}{cccc}
\hline & Lowland & \multicolumn{2}{c}{ Alluvial fan } \\
\cline { 2 - 4 } & Humic silt & Humic silt & Sand gravel \\
\hline$\theta_{\mathrm{s}}, \phi$ & 0.6 & 0.6 & 0.25 \\
$\theta_{\mathrm{r}}$ & 0.2 & 0.2 & 0.01 \\
$\alpha(/ \mathrm{m})$ & 2.0 & 2.0 & 2.5 \\
$n_{\mathrm{vg}}$ & 2.0 & 2.0 & 1.6 \\
$K_{\mathrm{s}}(\mathrm{m} / \mathrm{s})$ & $7.0 \times 10^{-5}$ & $7.0 \times 10^{-5}$ & $2.0 \times 10^{-4}$ \\
\hline
\end{tabular}

Table 2: Common parameters

\begin{tabular}{ccccccc}
\hline$\beta_{\mathrm{s}}\left(\mathrm{m}^{2} / \mathrm{N}\right)$ & $\beta_{\mathrm{w}}\left(\mathrm{m}^{2} / \mathrm{N}\right)$ & $c_{\mathrm{s}}\left(\mathrm{J} /\left(\mathrm{m}^{3} \mathrm{~K}\right)\right)$ & $c_{\mathrm{w}}\left(\mathrm{J} /\left(\mathrm{m}^{3} \mathrm{~K}\right)\right)$ & $b_{1}$ & $b_{2}$ & $b_{3}$ \\
$2.0 \times 10^{-8}$ & $4.5 \times 10^{-10}$ & $1.26 \times 10^{6}$ & $4.20 \times 10^{6}$ & 0.243 & 0.393 & 1.534 \\
\hline$T_{\mathrm{r}}\left({ }^{\circ} \mathrm{C}\right)$ & $a$ & $\sigma\left(\mathrm{W} /\left(\mathrm{m}^{2} \mathrm{~K}^{4}\right)\right)$ & $c_{\mathrm{p}}(\mathrm{J} /(\mathrm{kgK}))$ & $\beta$ & $z_{0}(\mathrm{~m})$ & $z_{\mathrm{obs}}(\mathrm{m})$ \\
20.0 & 0.2 & $5.670 \times 10^{-8}$ & 1005 & 0.5 & 0.1 & 2.0 \\
\hline
\end{tabular}




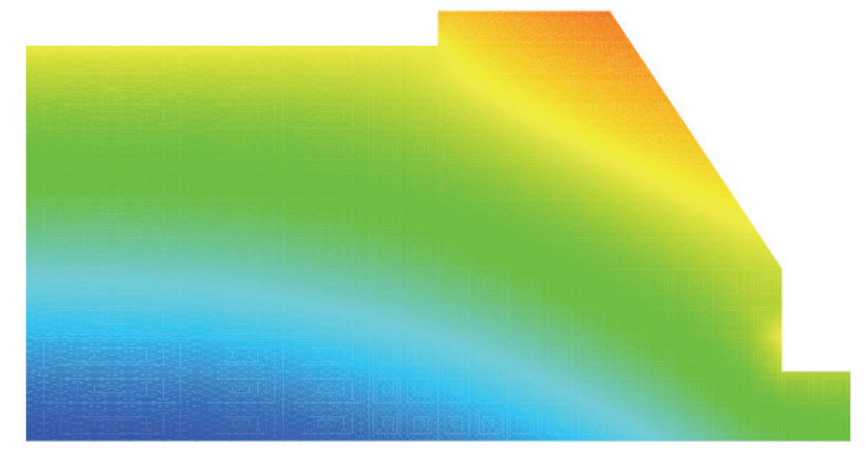

$\begin{array}{lllllll}-1.2 & -0.6 & 0.0 & 0.6 & 1.2 & 1.8 & 2.4\left(\mathrm{mH}_{2} \mathrm{O}\right)\end{array}$

Figure 3: Pressure head distribution in the lowland $(12: 00,8 / 13)$

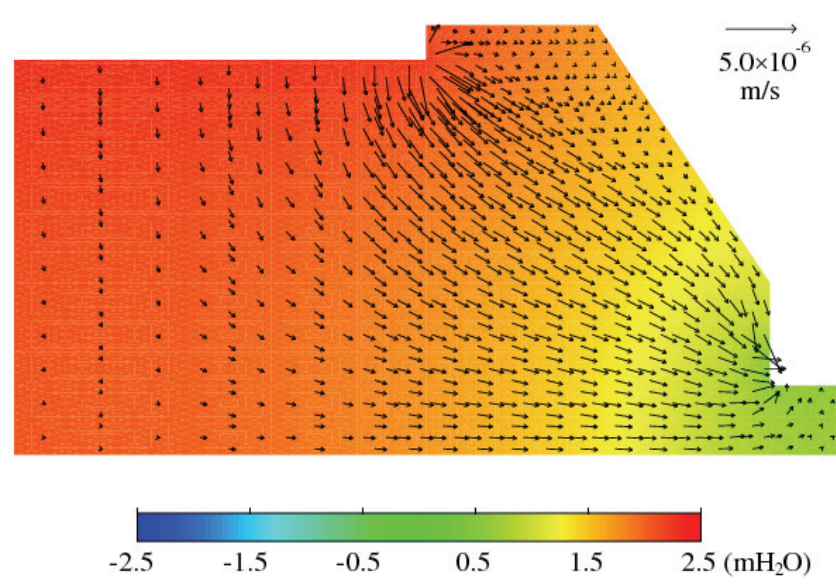

Figure 4: Total head and flow velocity distribution in the lowland (12:00, 8/13)
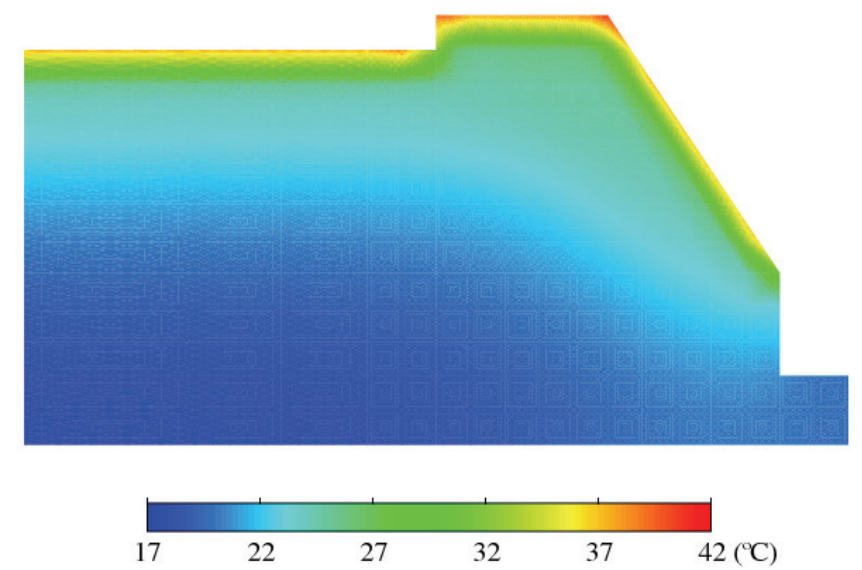

Figure 5: Soil temperature distribution in the lowland $(12: 00,8 / 13)$

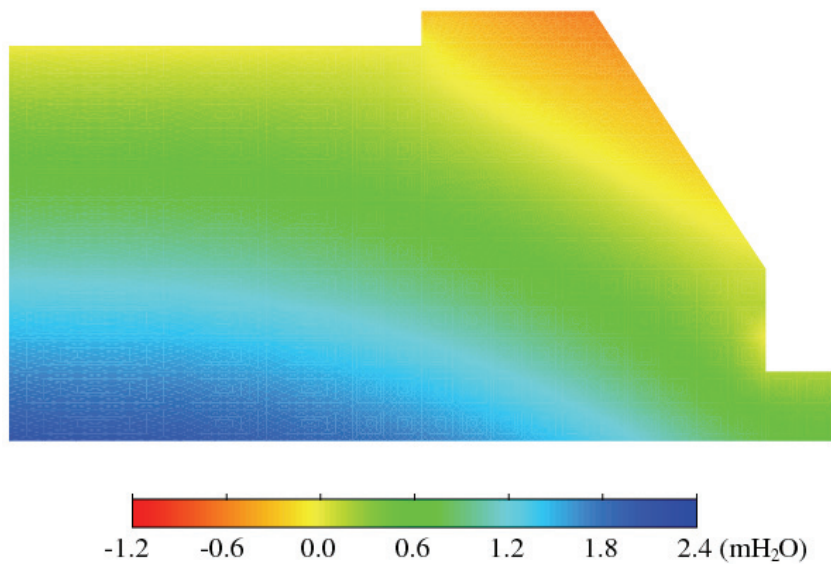

Figure 6: Pressure head distribution in the alluvial fan $(12: 00,8 / 13)$

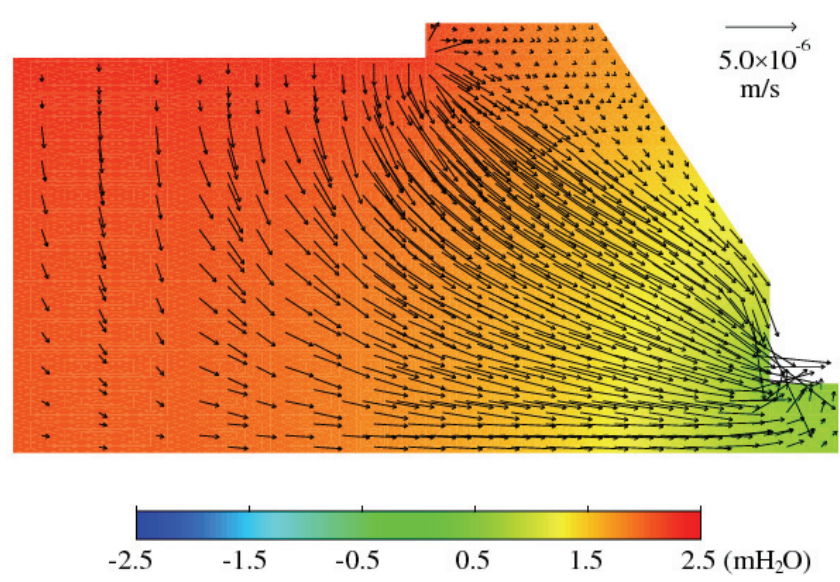

Figure 7: Total head and flow velocity distribution in the alluvial fan $(12: 00,8 / 13)$

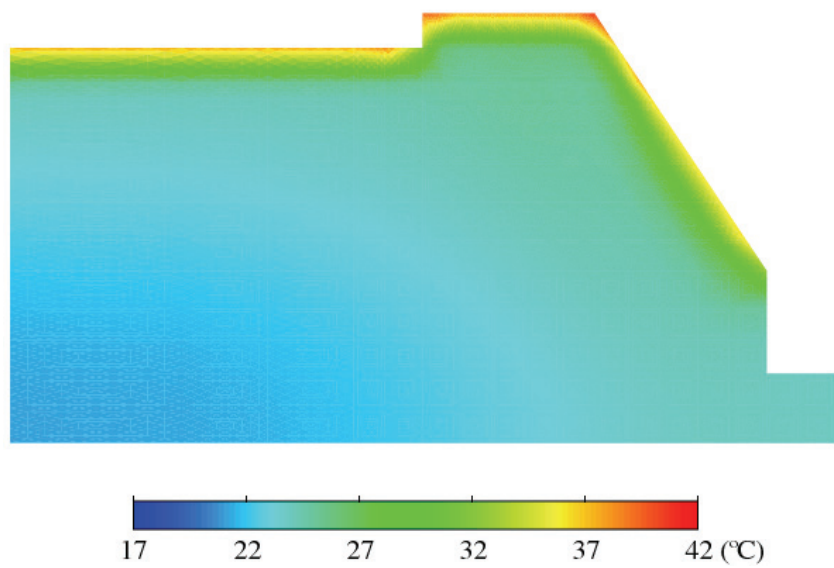

Figure 8: Soil temperature distribution in the alluvial fan $(12: 00,8 / 13)$ 


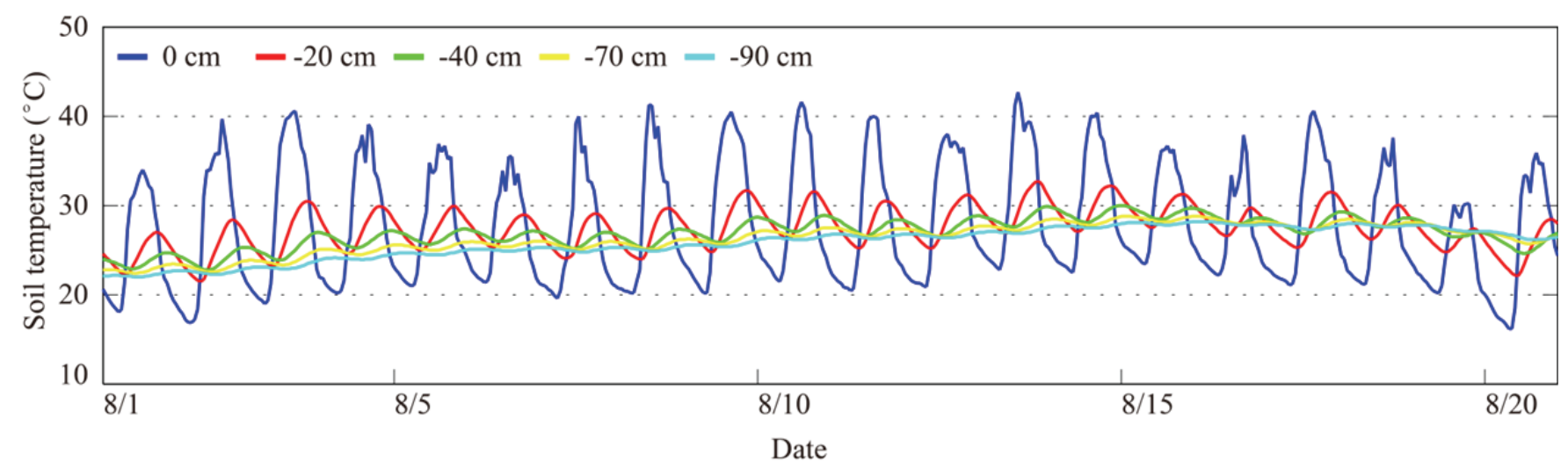

Figure 9: Time-varying soil temperatures in the alluvial fan

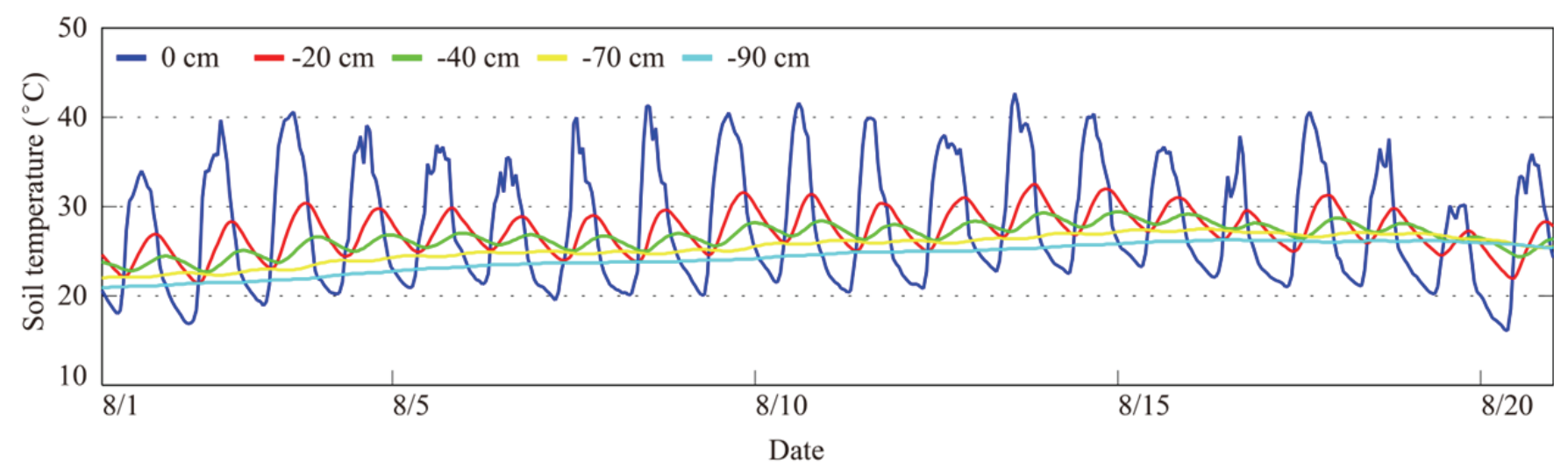

Figure 10: Time-varying soil temperatures in the lowland

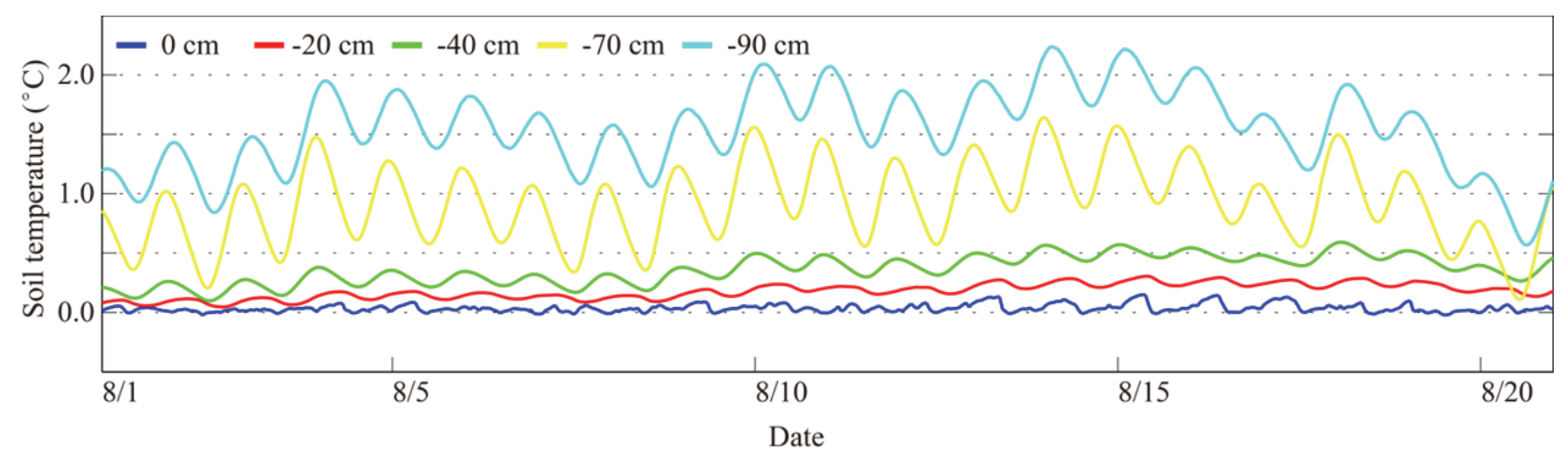

Figure 11: Difference in soil temperature between the alluvial fan and the lowland

These figures indicate that the difference in the soil temperatures between the two paddy fields increases with depth. The soil temperature in the lowland is $2.2^{\circ} \mathrm{C}$ lower at most than that in the alluvial fan because the heat capacity expressed in Eq. (7) in the lowland is larger than that in the alluvial fan due to the assumption of the soil texture of the 
subsoil. In the lowland paddy field, the subsoil is humic silt with relatively large porosity or volumetric water content, whereas the subsoil in the alluvial fan paddy field is sand gravel with relatively small porosity, which indicates that geological conditions influence soil temperature.

Finally, the average soil temperatures during the computation period (20 days) over the entire domain in the lowland paddy field and the alluvial fan paddy field are $22.4^{\circ} \mathrm{C}$ and $24.3^{\circ} \mathrm{C}$, respectively. Thus, saturated irrigation performs better in the lowland paddy field than in the alluvial fan paddy field.

Thus, consideration of the geological conditions of target paddy fields is concluded to be important when implementing saturated irrigation in order to prevent heat damage to rice plants.

\section{Conclusions}

In order to investigate the effects of saturated irrigation as a countermeasure against heat damage to rice plants during the ripening period, the influence of geological conditions on the soil temperature is clarified. As the geological conditions, a lowland paddy field and an alluvial fan paddy field are considered. In the two paddy fields, numerical simulations related to the soil water movement and heat transport are performed during the ripening period of rice.

The results indicate that the distribution of soil temperature in a paddy field depends on its geological conditions and that the soil temperature in the lowland paddy field becomes lower than that in the alluvial fan paddy field, and thus saturated irrigation achieves the intended purpose more efficiently in the lowland paddy field than in the alluvial fan paddy field.

\section{References}

[1] Anderson, M.P., and Woessner, W.W. (1992): Applied Groundwater Modeling, Simulation of flow and advective transport, Academic Press, Inc., p.41.

[2] Arai, T. (2004): Hydrology for Regional Analysis, Kokon Shoin, Publishers, 309p. (in Japanese).

[3] Buma, N., Takeuchi, J., Kawachi, T., Chono, S., Imagawa, C., and Ishida, K. (2012): A 2-D and 3-D composite dimensional fully coupled surface and subsurface flow model, J. Rainwater Catchment Systems, 17(2), pp.1-13.

[4] Celia, M.A., Bouloutas, E.T., and Zarba, R.L. (1990): A general mass-conservative numerical solution for the unsaturated flow equation, Water Resour. Res., 26(7), pp.1483-1496.

[5] Chung, S-O., and Horton, R. (1987): Soil heat and water flow with partial surface mulch, Water Resour. Res., 23(12), pp.2175-2186.

[6] Fujihara, Y., Toriyama, K., and Fujii, S. (2013): Effects of saturated irrigation on soil environment and rice quality, Water, Land and Environmental Engineering, 81(4), pp.273-276. (in Japanese).

[7] Huyakorn, P.S., and Pinder, G.F. (1983): Computational Methods in Subsurface Flow, Academic Press, 473p.

[8] Imagawa, T., Takeuchi, J., Kawachi, T., Chono, S., and Ishida, K. (2012): Sratistical analyses and modeling approaches to hydrodynamic characteristics in alluvial aquifer, Hydrol. Process., DOI: 10.1002/hyp.9538.

[9] Izumi, T., Fujihara, M., Takeuchi, J., and Kawachi, T. (2012): Inverse modeling for variably saturated water flow coupled with heat transport in field soil. Irrigation, Drainage and Rural Engineering Journal, 282, pp. 7-14.

[10] Kondo, J. (1994): Meteorology of the Water EnvironmentWater and Heat Balance of the Earth's Surface-, Asakura Shoten Press, 348p. (in Japanese).

[11] Kondo, J. (2000): Atmospheric Science near the Ground Surface, University of Tokyo Press, p.143. (in Japanese).

[12] Kondo, J., and Saigusa, N. (1994): Modelling the evaporation from bare soil with a formula for vaporization in the soil pores, J. Meteor. Soc. Japan, 72, pp.413-421.

[13] Morita, S. (2008): Prospect for developing measures to prevent high-temperature damage to rice grain ripening, Jpn. J. Crop Sci., 77(1), pp.1-12. (in Japanese with English abstract).

[14] Nagahata, H., Nakamura, K., Ino, M., Kuroda, A., and Hashimoto, Y. (2005): The cultivation management to make the occurrence of the milky white kernel and the cracked rice reduce under the high temperature during the ripening period, Bull. Ishikawa Agr. Res. Cent., (26), pp.1-10. (in Japanese with English abstract).

[15] Tomosho, T., and Yamashita, T. (2009): Problems and future directions of agricultural water management as measures against grain damage under high temperatures during ripening of rice, Tech. Rep. Natl. Inst. Rural. Eng. Japan, (209), pp.131-138. (in Japanese with English abstract).

[16] van Genuchten, M.Th. (1980): A closed-form equation for predicting the hydraulic conductivity of unsaturated soils, Soil Sci. Soc. Am. J., 44, pp.892-898.

Discussion open until December 31, 2014 